\title{
Second birth rates across Europe: interactions between women's level of education and child care enrolment
}

\author{
Jan Van Bavel and Joanna Różańska-Putek ${ }^{*}$
}

\begin{abstract}
Fertility differences in Europe are to a large extent due to parity progression after the first child. We therefore use data from the third round of the European Social Survey to investigate second-birth rates in 23 countries. Focusing on the role of education level and child care availability, we argue that child care provision is an important determinant of the opportunity cost of parity progression, particularly for highly educated women. We find that in countries where the highly educated have lower second birth rates than the less educated, total fertility tends to be low, and vice versa. In addition, the effect of the timing of the first child appears to be mediated by education level and child care availability: in countries where large proportions of young children attend formal child care, the more highly educated exhibit much higher second-birth rates, while child care availability does not affect parity progression for the less educated.
\end{abstract}

\section{Introduction}

In the transition to Europe's current low fertility levels, two stages can be distinguished. During the first stage, starting in the latter part of the nineteenth century in most European countries, married couples limited their family sizes by stopping their childbearing careers at both a lower age and a smaller final family size. This first stage primarily implied a declining incidence of high-parity births and the growing prevalence of the two-child family. It was temporarily and partly halted, or even somewhat reversed in some countries, during the 'baby boom' era in the mid-twentieth century. The timing of fertility shifted towards childbearing at younger ages during this halt. In the second stage, people started to postpone their first child (Lesthaeghe and Willems 1999). In northern, western, and

\footnotetext{
* Jan Van Bavel (correspondence author), Interface Demography research group, Vrije Universiteit Brussel (VUB), Brussels, Belgium. Email: jvbavel@vub.ac.be

Joanna Różańska-Putek, Interface Demography research group, Vrije Universiteit Brussel (VUB), Brussels, Belgium.
} 
southern European countries, this stage of postponement started in the 1970s or early 1980s. In central and eastern Europe (CEE), it started only in the early 1990s in most countries, after the fall of communism (Sobotka 2004). In recent decades, postponement has been compensated by recuperation at higher ages, resulting in some recovery of period fertility (Goldstein et al. 2009). The catching up is nevertheless incomplete so that many second- and higher-order births are foregone altogether. As a result, fertility remains well below the replacement level (Lesthaeghe and Willems 1999; Sobotka 2008).

Although the level of childlessness has been gradually increasing during the past decades in many countries (Sobotka 2004, Chapter 5), a drop in cohort firstbirth probabilities is not the major driving force behind the emergence of very low fertility in Europe (Billari and Kohler 2004). Cross-country fertility differences today are to a large extent due to differences in second-birth rates, and to a much lesser extent to an increasing rejection of parenthood. Apparently, the biological, psychological and social incentives remain strong enough for most people to want at least one child (Kohler et al. 2006; Morgan and Taylor 2006). The gap between lowest-low and ordinary low fertility crucially depends on parity progression after the first birth: second-birth rates are typically low in the very low fertility countries of southern as well as central and eastern Europe. A notable exception is Germany, where low fertility is clearly linked with high childlessness rather than with very low parity progression after the first birth (Sobotka 2008: 39).

There are signs that second births may become even more critical for European fertility levels in the future. Among people who do want to experience parenthood, the two-child norm seems to have weakened somewhat in recent decades (Goldstein et al. 2003; Breton and Prioux 2005). In most countries of the former EU-12, the proportion of young women preferring just one child doubled during the 1980s (Coleman 1996). In Austria, mean ideal family sizes have already reached the below-replacement level among recent generations of young adult women aged 25-39 (Testa 2007). According to the 'low fertility trap hypothesis', persistently low fertility levels may lead to declining fertility intentions and ideals if new generations of Europeans, brought up in a lowfertility context, adopt and intensify the childbearing strategies of their parents and peers (Goldstein et al. 2003; Lutz et al. 2005). This intergenerational socialisation effect may already be observable in German-speaking countries (Testa and Grilli 2006). Low mean personal ideal family sizes have also been reported in southern European countries such as Italy and Spain (Testa 2007).

This paper addresses differences between second-birth rates in 23 European countries and examines several questions. First, how large are the differences between second-birth rates in Europe? To what extent are second-birth rates affected by the postponement of first births? Some postponement effect is to be expected in all cases in the sense that the postponement of parenthood is bound to spill over to some extent to the quantum of fertility, starting with parity progression to the second birth (Billari and Borgoni 2005). How do such 
postponement effects on second-birth rates vary by social group and country? More specifically, this paper will examine social differences according to women's educational levels and study differences between countries, by focusing on the role of child care enrolment rates. We will also look at micro-macro interactions: how does the micro-level effect of education on the second-birth rate depend on macro-level enrolment rates in formal child care?

\section{Micro- and macro-influences on second-birth rates}

Differences in the extent to which there is any catching up on delayed births at a later age or not (i.e. the quantum implications of tempo shifts) are likely to be an important factor behind the divergence of fertility levels in Europe. Catching up, in turn, is expected to be influenced by the level of education at the micro-level, and by formal child care availability at the macro-level.

\subsection{The role of education}

According to Kohler et al. (2006), the postponement of first births is associated with increasing investments in human capital, particularly by women, implying a higher wage-earning potential. Women who postpone motherhood are often those with more work experience and higher wages prior to their first births. This postponement-induced increase in women's actual and potential wages translates into higher opportunity costs, not only of first but also of second children. Given that the incentives to have at least one child still appear to be very strong, the higher child-costs associated with delaying the first child are likely to translate particularly as lower parity progression rates after the first birth.

This hypothesis begs to be investigated systematically and thoroughly. We need to find out how it can be reconciled with the observation, made for a number of countries, that more highly educated women tend to exhibit a weaker negative postponement effect on second-birth rates and shorter birth spacing than less educated women (Köppen 2006; Neels 2006), while we know that the wageearning potential of the former group is higher. More generally, it has been found for several countries that more highly educated women, once they leave school and university, have higher birth rates than their less educated peers. This extends to second-birth rates (Hoem and Hoem 1989; Kreyenfeld 2002; Oláh 2003; Köppen 2006; Neels 2006; Lappegård and Rønsen 2005; Gerster et al. 2007; Klesment and Puur 2009). There is consequently some evidence of highly educated women catching up more after postponement. Nonetheless, other studies do not confirm such results or effects (e.g. Liefbroer and Corijn 1999; Kantorova 2004; Gerster et al. 2007). For Denmark, although the education level was positively associated with second-birth probabilities, there was no evidence that 
this was due to any faster catching up by highly educated women after timing their first birth later (Gerster et al. 2007).

There are several reasons for expecting highly educated women to catch up faster after postponement. First, all else being equal, a higher earning potential facilitates a bigger family thanks to an income effect. Second, highly educated women may be motivated to concentrate their births in a shorter period of time in order to resume their professional career sooner after attaining their desired family size (Brewster and Rindfuss 2000; Köppen 2006). Third, a higher wageearning potential need not translate directly as higher opportunity costs. More highly educated women tend to have more resources and skills to reconcile paid work with raising more than one child. The double burden for mothers who pursue a professional career can be diminished in at least two ways. On the one hand, their partners can contribute more to household chores and child care (Oláh 2003; Torr and Short 2004) while on the other, the availability of formal child care may facilitate investing in their professional career, especially in the context of dual-earner families, a most common pattern among women with higher education degrees (Van Dijk and Siegers 1996; De Henau et al. 2007; Lappegård 2010). Finally, the relative cost of non-family care may be lower for them than for less educated women (Ermisch 1989; Kravdal 2007).

\subsection{Child care and the combination of paid work and family life}

The compatibility of professional work and family life may be at the heart of the differential effects of tempo shifts on the quantum of fertility, not just at the micro level within particular populations but also at the cross-country level in Europe. The differences between countries with high versus low compatibility of paid work and parenting may have important implications for the effects of delayed first births on second-birth rates. These effects are expected to be particularly strong in the context of inflexible labour markets and insufficient availability of child care facilities (Kohler et al. 2006). In contrast, if child care is more abundantly available and it is culturally acceptable to use it even with very young children, the opportunity costs of parity progression will go down (Rindfuss et al. 2007). This would hold true in particular for the highly educated, given that they have the highest earning potential and, hence, the highest opportunity costs if parity progression cannot be combined with continued activity in the labour market (Kravdal 2007; Haan and Wrohlich 2009).

A range of policy measures may facilitate or hinder the reconciliation of work and family life. In this paper, we focus on formal child care only. The use of formal child care depends on four major factors: its affordability, its availability, the quality of care and its social acceptance (Van Dijk and Siegers 1996; Brewster and Rindfuss 2000; Kreyenfeld and Hank 2000; Viitanen 2005; Rindfuss et al. 2007). The importance of these different aspects varies across Europe resulting in 
diverse child care enrolment rates. For example, in Germany and Italy, the number of day nurseries and nursery schools is very limited and opening hours usually do not fit the schedule of working parents (Kreyenfeld and Hank 2000; Del Boca 2002). In contrast, in the United Kingdom even if services are available and new places may be produced easily (as their number is to a larger extent subject to the free-market principle of supply and demand), the cost of formal child care is high making it unaffordable for many (Viitanen 2005). Additionally, cultural beliefs may discourage parents from sending their children to public child care institutions and therefore the use of non-formal care may be very important - as it is e.g. in southern Europe (Baizán 2009; Del Boca 2002). In central and eastern Europe such resistance may be combined with the shortage of child care services evoked after the collapse of the previous political and economical system as well as with the low trust in the quality of public child care (Szelewa and Polakowski 2008; Robila 2009; Hašková 2010).

In fact, all over Europe, parents considering family enlargement may be more aware than childless persons of the difficulties and constraints that emerge from the double burden of a professional activity and family obligations - with, mostly for the women, a second shift awaiting them at home, once they have finished their paid work day (Brewster and Rindfuss 2000; Dribe and Stanfors 2009). Their further childbearing may also be influenced by their knowledge of the local child care situation. If their experience is negative, they may find it too risky to decide on having another child. This may help explain differences in second-birth rates across Europe.

On the one hand there are countries with relatively high fertility. These are mostly in the Nordic region and in western Europe. France, for example, is wellknown as a country with generous family policies, part of it particularly targeting the promotion of third-order births (Ekert-Jaffé et al. 2002; Breton and Prioux 2005), and potentially stimulating second births as well. In the Netherlands parttime work schemes typically allow mothers to bring up children while still remaining in the labour market (Mills et al. 2008). In the Nordic countries too, some $40-50 \%$ of mothers of pre-school children combine part-time jobs with childrearing (Brewster and Rindfuss 2000). This is facilitated by the availability of formal child care services. In France and the Netherlands, the provision of day care for children under 3 years of age is quite high, with a level close to the target of 33\% set by the European Council at the Barcelona Summit in 2002 (OECD 2008; European Commission 2008). In Scandinavian countries enrolment rates into day nurseries and nursery schools are among the highest in Europe (Hoem 2005; OECD 2008). In Sweden almost $80 \%$ of pre-school children attended formal child care units in 2000 (Dribe and Stanfors 2009).

In contrast, the use of formal child care is typically low in the low-fertility countries of southern and central and eastern Europe as well as in Germanspeaking countries (e.g. Del Boca 2002; Rostgaard 2004; De Henau et al. 2007; Kotowska and Matysiak 2008; Baizán 2009). This may be due to the low 
provision of such services, or, as mentioned earlier, to more cultural constraints such as attitudes towards childrearing. It is most likely that both components play a role here, with a mutually reinforcing effect.

As to post-communist countries, parents there encounter many obstacles to combining childbearing and childrearing with a professional career. First of all, a lot has changed in terms of family policy and state interference in CEE during recent decades, after democratisation and economic and social reforms (e.g. Sobotka 2002; Neyer 2006; Kotowska and Matysiak 2008; Szelewa and Polakowski 2008). Under state socialism, job positions as well as free places in day nurseries and nursery schools were guaranteed or easily available (Rostgaard 2004; Robila 2009). At the same time, career opportunities were limited, but lowor mid-income positions were obtainable without effort thanks to a doctrine of full employment. Nowadays, the labour market is more demanding and child care is less accessible. Second, attitudes towards work have changed: there are more opportunities to pursue a professional career and there are more people willing to do so. Third, both men and women are more likely to stay longer in education, and the number of female university graduates has boomed in particular. Finally, the economic situation is not stable and uncertainty is a trait of many spheres of life (Philipov 2002). As result, having a larger family is a bigger challenge than it used to be (e.g. Kotowska et al. 2008; Spéder and Kamarás 2008).

In Germany the work-family conflict is also a salient and complex issue. While unemployment has been high in eastern Germany, in western Germany the belief is widespread that mothers themselves should be the (full-time) care-givers of very young children; child care provision is limited and inadequate, with hardly any private child care institutions (Kreyenfeld and Hank 2000; De Henau et al. 2007). This leads to polarisation into two groups of women: a work-oriented group and those who devote themselves to childbearing and home-making (Köppen 2006). Concerning higher-order births, some authors claim that finding the appropriate care for children and maintaining their paid jobs is nearly impossible for western German women (Kreyenfeld and Hank 2000).

In general, previous research confirms the role of child care availability and affordability in facilitating female labour force participation rates (Gustafsson and Stafford 1991; Van Dijk and Siegers 1996; Kreyenfeld and Hank 2000; De Henau et al. 2007; Rindfuss et al. 2007). However this effect is not consistent throughout Europe (see e.g. Gauthier 2007 for an overview). The availability of child care usually seems to matter more than its cost. In western Germany, for example, formal child care is hardly available anyway, so its cost cannot play a significant role. Availability is the crucial issue there. In contrast, in the market setting of the United Kingdom the cost of child care is found to influence its use (and female labour force participation), although there is evidence of unmet demand as well. The results of a simulation exercise from the same study suggest that a substantial percentage of families have a preference for informal child care even in spite of 
heavy subsidies for public day care institutions (Viitanen 2005). This supports the view that attitudes about child care use play an important role as well.

The availability, and the use, of child care facilitate the reconciliation of work and family. Most studies focus on the impact of formal child care on female employment but some investigate directly its influence on fertility rates. A positive relationship between child care coverage was found for Spain for all births-i.e. first births as well as higher-order ones (Baizán 2009). For Sweden such results could not be detected (Andersson et al. 2004). The examination of child care characteristics (provision rate, child-to-staff-ratio and costs of care to parents) led to the observation that a good coverage of child care and efficient family policies in Sweden may enable parents to have the desired offspring no matter where they live. Also for western Germany there is no clear evidence that the regional availability of day-care slots affects childbearing decisions or mothers' employment (Hank and Kreyenfeld 2003). However, in contrast to the Swedish case, it was argued that this may be due to the total lack of any feasible child care system in Germany. For Italy, representing yet another socio-cultural setting, there is evidence that child care availability has a positive impact on both female labour force participation and fertility (Del Boca 2002).

Based on these earlier research findings, we expect that the transition to the second birth is made more easily in countries with adequate child care provisions and regulations aimed at diminishing the double burden of females. This is likely to be the case, very broadly speaking for the time being, in north-western Europe (Oláh 1998; 2003; Del Boca 2002; Köppen 2006; Brodmann et al. 2007). By contrast, we think that second-birth rates will be the lowest in countries where such provisions are poorly developed, like in southern and post-communist central and eastern European countries.

\section{Questions and hypotheses}

Summing up, we will address the following research questions and hypotheses. First, how large are differences between second-birth rates in Europe and how are they distributed geographically across Europe? From earlier research with register data we expect second-birth rates to be lowest in southern, central, and eastern Europe (including the Balkans, and with the exception of Germany, see Sobotka 2008: 39), and highest in western and northern Europe.

Second, how large are the effects of first-birth timing on second-birth rates and how do they vary by country? We expect that differential postponement effects between countries can be explained, at least to some extent, by the differential composition of European countries in terms of women's education levels and by the extent of child care enrolment. This relates and leads to the third and fourth research question. 
Third, how large is the effect of women's education level on second-birth rates and how does this vary by country? In general across countries, we expect that highly educated women make the transition to second births faster than less educated women. More specifically, we expect that highly educated women tend to catch up faster than less educated women after the postponement of parenthood. In other words, our hypothesis runs that there is an interaction between the age at first birth and the education level: the negative effect of a high age at first birth on the second-birth rate is expected to be weaker for women with a high education level. Conversely, the postponement effect is expected to be stronger for women with a low education level.

Fourth, how large is the effect of a country's enrolment rate in formal day care services and how does this vary by education level? We expect that countries with higher enrolment rates tend to exhibit higher second-birth rates. In addition, we expect that formal child care enrolment particularly stimulates second-birth rates among the highly educated, since these are the ones that have the highest earning potential and are therefore faced with the highest opportunity costs if there is reduced availability of child care services. In other words, our final hypothesis is that there is a cross-level interaction effect between the individual education levels on the one hand and the country-level child care enrolment rate on the other hand.

\section{Data}

In our analysis we use data from the third round of the European Social Survey (ESS), edition 3.2, released in October 2008. Fieldwork was carried out using face-to-face interviews between late June 2006 and November 2007. The ESS is a biennial, cross-national, academically driven and partly repetitive survey that allows exploring behaviour and attitudes of Europeans. The third round of the ESS was conducted in twenty-five countries: Austria, Belgium, Bulgaria, Cyprus, Denmark, Estonia, Finland, France, Germany, Hungary, Ireland, Latvia, the Netherlands, Norway, Poland, Portugal, Romania, Russia, Slovakia, Slovenia, Spain, Sweden, Switzerland, Ukraine and the United Kingdom (ESS Round 3, 2006 and 2008).

\subsection{Selection of cases}

We excluded Russia and Ukraine from the analysis because we think that the cultural, institutional, historical, political and demographic differences to the rest of the European continent are too big to allow useful comparison here. As a result, our study covers the remaining 23 countries. This holds for most of the analyses but not for the final regression model that includes national measures for enrolment in child care (see below). For that model, we had to limit the number of 
countries to 16 since we lacked the comparable information on day care enrolment rates for Bulgaria, Cyprus, Estonia, Latvia, Romania, Slovenia and Switzerland.

ESS3 respondents are selected based on four criteria: age, marital status, number of children and living with a partner. We include only those respondents who already had given birth to or fathered at least one child, never experienced a divorce and were living with a partner at the time of the interview. This selection was made in order to strike a balance between achieving reasonable homogeneity on the one hand and retaining a sufficient number of cases on the other. Divorcees were excluded because a divorce interrupts the process described in the theoretical section and in the hypotheses formulated above. Also, the number of stepchildren will be relatively high if we include the divorced. The role of divorce in second-birth rates merits a separate analysis and is not the focus of this paper. At the same time, we did not want to limit the analysis to married people even if a similar argument could be made about the never married and (possibly) separated. Limiting the analysis to married couples would have implied that we retained a very small and selective sample in a number of countries.

ESS3 provides information on respondents' partners as well, and we restricted the age- and cohort range by selecting only couples when both his and her age was between 15 and 45 years (both age limits included). Including older people would have extended the analysis to older cohorts, who had given birth in time periods not covered by the theoretical rationale for this paper, i.e. before the 1980s. By applying these selection criteria, and after dropping cases with missing values for crucial variables, we achieved a sample size of 6177 couples.

\subsection{Variables used}

Table 1 gives basic descriptive statistics for the variables that will be used in the analysis. The following paragraphs discuss the construction of the variables about education and enrolment in child care. 
Table 1:

Descriptive statistics of variables used in the models; never divorced couples with at least one child, both partners aged 15 to 45 years

\begin{tabular}{|c|c|c|c|c|c|c|}
\hline & Mean & $\begin{array}{c}\text { St. } \\
\text { dev. }\end{array}$ & Min & $\operatorname{Max}$ & $\mathrm{N}$ & $\%$ \\
\hline \multicolumn{7}{|c|}{ Analysis without child care enrolment (models I-IV) } \\
\hline \multicolumn{7}{|c|}{ Having at least two children (dependent variable) } \\
\hline - No & & & & & 2159 & 34.9 \\
\hline - Yes & & & & & 4027 & 65.1 \\
\hline \multicolumn{7}{|c|}{ Individual level characteristics of women } \\
\hline Current age of woman & 34.45 & 5.67 & 15 & 45 & 6186 & \\
\hline Age at first birth & 25.65 & 4.63 & 14 & 44 & 6177 & \\
\hline Year first child was born & 1997 & 5.9 & 1960 & 2007 & 6185 & \\
\hline \multicolumn{7}{|l|}{ Level of education } \\
\hline - Low & & & & & 1462 & 23.8 \\
\hline - Medium & & & & & 2879 & 46.9 \\
\hline - High & & & & & 1800 & 29.3 \\
\hline \multicolumn{7}{|c|}{ Analysis with child care enrolment (model V) } \\
\hline \multicolumn{7}{|c|}{ Having at least two children (dependent variable) } \\
\hline$-\mathrm{No}$ & & & & & 1563 & 34.0 \\
\hline - Yes & & & & & 3042 & 66.0 \\
\hline \multicolumn{7}{|c|}{ Individual-level characteristics of women } \\
\hline Current age of woman & 34.68 & 5.57 & 5 & 45 & 4605 & \\
\hline Age at first birth & 26.22 & 4.56 & 15 & 44 & 4601 & \\
\hline Year first child was born & 1998 & 5.8 & 1979 & 2007 & 4604 & \\
\hline \multicolumn{7}{|l|}{ Level of education } \\
\hline - Low & & & & & 1191 & 26.0 \\
\hline - Medium & & & & & 1903 & 41.7 \\
\hline - High & & & & & 1473 & 32.3 \\
\hline \multicolumn{7}{|c|}{ Characteristics of child care (country-level variable) } \\
\hline $\begin{array}{l}\text { Enrolment in day care below age } 3 \\
\text { in } \% \text {, ca. } 2004\end{array}$ & 23.22 & 14.8 & 2 & 61.7 & 16 & \\
\hline
\end{tabular}

Source: European Social Survey Round 3 Data 2006 - 2007 


\subsubsection{Education}

ESS3 records the highest educational degree obtained by respondents and distinguishes between 7 levels: (0) not completed primary education, (1) primary or first stage of basic, (2) lower secondary or second stage of basic, (3) upper secondary, (4) post secondary, non-tertiary, (5) first stage of tertiary and (6) second stage of tertiary. The same information was asked for respondents' partners. Based on the information about him and her, we constructed dummies for three broad educational levels: low (categories 0-2 of the original ESS classification), medium (categories 3-4) and high (categories 5-6).

\subsubsection{Child care enrolment}

We used the OECD Family Database for information on child care enrolment rates across Europe. More specifically, we selected the extent of enrolment of children aged 0-2 in day care. This is the percentage of 0-2 olds in formal day care facilities. These services include day nurseries and other child care centres for the very young, care provided by registered childminders looking after one or more children at their own places, and by non-family members at the child's home (OECD 2008). For most countries, the figures refer to the year 2004 (see below for the exceptions).

We chose this indicator because, in contrast to indices based on the percentage of GDP spent on family services or policies, it is not directly influenced by the number of young children, and hence, by the second-birth rate that we will be modelling as a dependent variable. As this measure is relative to the number of children in a country, we believe that it offers a reasonable, though crude, assessment of formal child care practice in that country. 'Reasonable' but not 'ideal': the variable that we would ideally want to include in the analysis, i.e. some measure of child care availability (how difficult it is for a couple to find day care if they want and need it), is not available in a cross-nationally comparative way. To some extent, enrolment rates will be driven by demand factors: if a large proportion of couples want to bring their young children to day nurseries, enrolment rates will be higher, all else being equal. At another level, public policy will influence enrolment rates as well: if many couples want to bring their young children to day nurseries but policy does not stimulate formal child care provisions, enrolment rates will be lower than in countries where formal day care facilities are subsidised by the government. 
Still, there are a number of concerns about these data. First, OECD collects the data reported in its international database from various sources. The quality of the enrolment data obviously depends on the collection method. Especially if small or medium-sized household surveys are used, sampling bias may arise (OECD 2008). Second, the year of reference is 2004, but there are several exceptions (Ireland: 2000; Germany, Poland: 2001; France: 2002; Finland, Norway, Slovakia: 2003; and Denmark: 2005). Third, as mentioned before, no data were available for Bulgaria, Cyprus, Estonia, Latvia, Romania, Slovenia and Switzerland which leads to the exclusion of these countries from our last model. Fourth, the OECD figures we used do not take into account the weekly amount of time children spend in day care. Also, some children may be counted double when they are enrolled in more than one part-time programme. For example, in some countries nursery schools are open only for half a day. It is therefore possible that a child attends nursery school in the morning and then family day care in the afternoon. These categories are commonly reported together and so the same child could be counted twice. This leads to an over-estimated participation rate. Fifth, enrolment rates are country-level averages. In some countries, enrolment in day care differs substantially by region, both for cultural and institutional (policy-related) reasons. This is the case, for example, in Belgium and Germany. This undermines the meaning and statistical power of the country level average.

Finally, maybe the most important limitation is that most births analysed in this paper occurred years before 2004. Enrolment rates are bound to have changed between the years when the analysed couples were having their children. As a working assumption, we assume that the rank order of countries will not have changed a lot and that the differences between countries observed around 2004 are a reasonable proxy for the actual enrolment rates around the time of the births we are analysing. 
Figure 1:

Enrolment in day care for children under 3

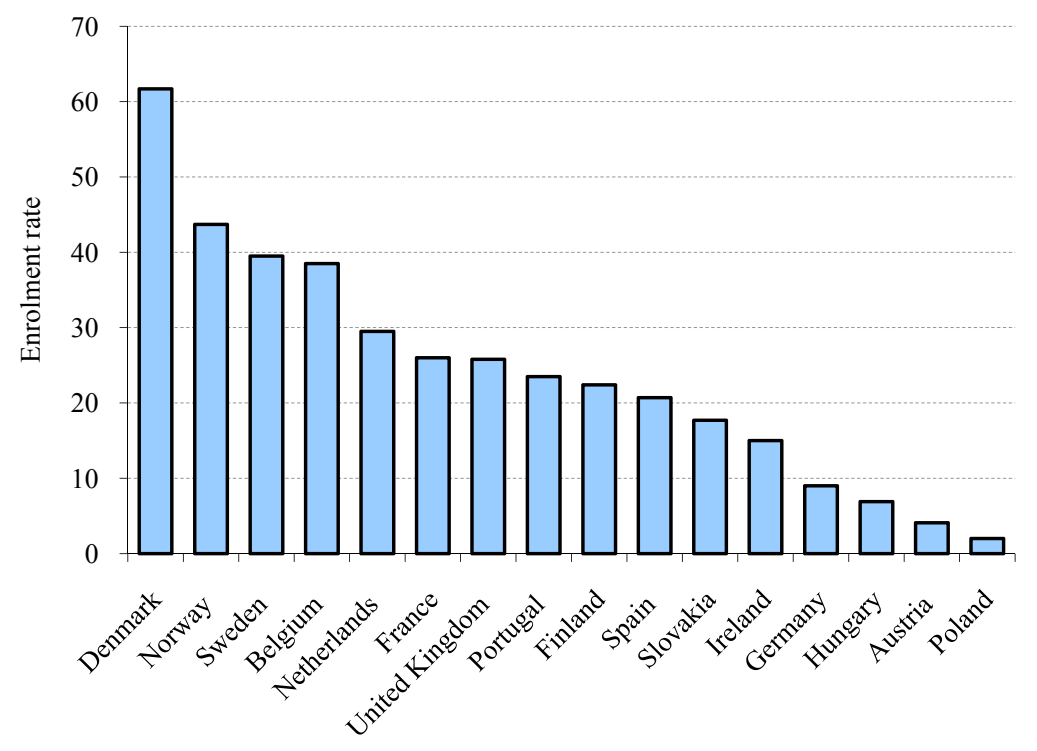

Source: OECD 2008

Overall, there is a clear pattern in day care use across Europe. First, as can be seen in Figure 1, differences in child care service use are large. While the average rate is $23 \%$, there is a large variety in percentages of $0-2$ years-old children enrolled in formal child care across Europe. High enrolment rates are observed in Nordic countries and in Belgium. These are countries with well-established child care policies, often assessed as generous welfare regimes. Low rates are reported in countries from central and eastern Europe: Poland (showing the lowest rate with 2\%), Hungary, Germany and Austria (see Figure 1). As mentioned before, we expect this to reflect interplay between cultural, social and economic processes that result in lower child care provision and lower willingness to use such services.

\section{Method}

Since we only know children's year of birth (not day or month), second-birth rates are analysed with discrete-time event history regression models. More specifically, we model the yearly probability of progression to the second birth for people who have had a first birth, using multilevel logistic regression: 


$$
\begin{aligned}
& \operatorname{logit}\left(h_{i j}(t)\right)=\beta_{0 j}+\beta_{1} t+\beta_{2} t^{2}+X_{i j} \beta_{3}+Z_{i j} \beta_{4 j} \\
& \beta_{0 j}=\gamma_{00}+\left(\gamma_{01} C_{j}\right)+u_{0 j} \\
& \beta_{4 j}=\gamma_{40}+\left(\gamma_{41} C_{j}\right)+u_{4 j} \\
& u_{0 j} \sim N\left(0, \sigma_{00}^{2}\right) ; \quad u_{4 j} \sim N\left(0, \sigma_{40}^{2}\right) ; \quad \operatorname{cov}\left(u_{0 j}, u_{4 j}\right)
\end{aligned}
$$

where

- $\quad h_{i j}(t)$ is the discrete time hazard rate of having a second birth in year $t$ for couple $i$ in country $j$;

- $\quad t$ is the number of years elapsed since the birth of the first child (with $t=0$ being the year of birth of the first child);

- $\quad X_{i j}$ is a vector of individual characteristics that are modelled to only have fixed effects;

- $Z_{i j}$ is a vector of individual characteristics that are modelled to have effects that vary by country $j$;

- $\quad C_{j}$ is a vector with country characteristics.

(All other parameters have the conventional meaning in random effects multilevel modelling). As can be seen from the equation, we assume that the hazard rate is a second-order polynomial function of the number of years since the first birth, allowing it to first go up, reach a maximum, and then go down. All models to be presented include a random intercept $\left(\beta_{0 j}\right)$ to explicitly allow countries to have different second-birth rates. In the more complex models, the effects $\beta_{4 j}$ of some individual-level characteristics are allowed to vary by country.

While fitting the models, we applied the ESS design weights in order to account for differences between countries in sampling design. We did not apply population weights because our aim is not to estimate an average European effect (which would be dominated by the big countries due to their larger population size) but rather to look at differences between countries.

It should be noted that, from a counterfactual perspective, the regression parameters obviously cannot be interpreted as estimates of a 'pure' causal effect on the second-birth rate (Engelhardt et al. 2009). Indeed, the explanatory variables can easily be argued to be endogenous. For example, if many women in a given country want to have a second child while wanting to continue working for pay, they might put pressure on their politicians to invest in making formal child care widely available. The positive association between child care availability and second-birth rates would then be caused by the so-called 'exogenous' preference structure of these women. Therefore, our use of multilevel regression modelling has more modest aims here, i.e. to describe how a set of variables is associated with second-birth rates after controlling for the other ones (see Angrist and Pischke 2009 for a lucid discussion of different uses of regression). 
Also, when interpreting the effects of age at first birth and education, it should be kept in mind that only people who have given birth to at least one child are selected to be part of the analysis. As a result, the estimated effects on secondbirth rates will to some extent reflect selection effects. For example, highly educated women who are strongly family-oriented and have their first child at a relatively early age will be more likely to be included in the analysis than highly educated women who prefer to first pursue a career, since the latter may not even have had their first child (yet) at the time of the survey. In order to gain insight in the importance of such selection effects, first- and second-birth rates should be modelled simultaneously, with a correlated term included in all equations to capture part of the unobserved heterogeneity. Previous studies have shown that a modelling strategy of this type may strongly alter the estimated effects of the education level; a positive effect may even turn negative (see for example Kreyenfeld 2002; Kravdal 2001). We have not followed such a modelling strategy here, so the results presented below are selective in the sense that they hold only for people who have already had their first child, and who thus by definition form a special, more family-oriented group indeed. This does not invalidate or bias our results, it only limits their applicability.

\section{Results}

We start with a simple model (Model I) that only includes the second-order polynomial function of the number of years elapsed since the first birth, the calendar year when that first birth occurred (centred around its median value of 1996), and a random country effect, assumed to be a draw from a normal distribution. The parameters of this and all other models are presented in Table 2.

First note that the fitted linear time trend is negative and statistically significant, meaning that second-birth rates were generally going down in Europe. We will not discuss this trend any further. The fitted shape of the baseline hazard rate is depicted in Figure 2. On average across Europe, the probability that a second birth occurred within the same calendar year as the first birth is estimated to be around 5\%. This conditional probability (given that a first birth has, and that a second birth has not yet occurred) then rises to reach a maximum in the fifth year after the first birth: if parity progression had not yet occurred by then, the probability that it does occur that year is around $23 \%$. For the remaining parents with a single child, the hazard rates then goes down again. 
Table 2:

Progression to the second birth: results of multilevel logistic regression for all five models presented in this article

\begin{tabular}{|c|c|c|c|c|c|c|c|c|c|c|c|c|c|c|c|}
\hline & \multicolumn{2}{|c|}{ Model I } & \multicolumn{3}{|c|}{ Model II } & & \multicolumn{2}{|c|}{ Model III } & & \multicolumn{2}{|c|}{ Model IV } & \multicolumn{4}{|c|}{ Model V } \\
\hline & b & s.e. & & b & s.e. & & b & s.e. & & b & s.e. & & b & s.e. & \\
\hline \multicolumn{16}{|l|}{ Fixed effects } \\
\hline Intercept & -2.999 & 0.092 & $* * *$ & -2.955 & 0.1 & $* * *$ & -3.036 & 0.089 & $* * *$ & -3.077 & 0.096 & $* * *$ & -3.126 & 0.16 & $* * *$ \\
\hline Year of $1^{\text {st }}$ birth & -0.033 & 0.003 & $* * *$ & -0.032 & 0.004 & $* * *$ & -0.033 & 0.004 & $* * *$ & -0.033 & 0.004 & $* * *$ & -0.034 & 0.004 & $* * *$ \\
\hline Years since $1^{\text {st }}$ birth & 0.728 & 0.021 & $* * *$ & 0.729 & 0.022 & $* * *$ & 0.739 & 0.022 & $* * *$ & 0.741 & 0.022 & $* * *$ & 0.786 & 0.026 & $* * *$ \\
\hline Years since $1^{\text {st }}$ birth squared & -0.073 & 0.002 & $* * *$ & -0.073 & 0.002 & $* * *$ & -0.073 & 0.002 & $* * *$ & -0.073 & 0.002 & $* * *$ & -0.079 & 0.003 & $* * *$ \\
\hline Age at $1^{\text {st }}$ birth (centred) & & & & -0.004 & 0.005 & & -0.01 & 0.011 & & -0.043 & 0.014 & $* *$ & -0.025 & 0.013 & + \\
\hline Age at $1^{\text {st }}$ birth squared & & & & -0.001 & 0.001 & + & -0.004 & 0.001 & $* * *$ & -0.004 & 0.001 & $* * *$ & -0.005 & 0.001 & $* * *$ \\
\hline \multicolumn{16}{|l|}{ Level of education (ref.=Low) } \\
\hline - Middle & & & & -0.08 & 0.047 & + & -0.053 & 0.061 & & 0.001 & 0.055 & & -0.119 & 0.105 & \\
\hline - High & & & & 0.071 & 0.054 & & 0.08 & 0.078 & & 0.105 & 0.074 & & -0.067 & 0.149 & \\
\hline \multicolumn{16}{|c|}{ Interaction: Age at $1^{\text {st }}$ birth $x$ Level of education (ref. $=$ Low) } \\
\hline - High & & & & & & & & & & 0.051 & 0.013 & $* * *$ & 0.048 & 0.015 & ** \\
\hline - Middle & & & & & & & & & & 0.044 & 0.011 & $* * *$ & 0.052 & 0.013 & $* * *$ \\
\hline \multicolumn{16}{|c|}{ Enrolment in day care for the below age 3 in $\%$, ca.2004 } \\
\hline - High & & & & & & & & & & & & & 0.012 & 0.005 & * \\
\hline \multirow[t]{2}{*}{-Middle } & & & & & & & & & & & & & 0.008 & 0.004 & + \\
\hline & & St.dev. & & & St.dev. & & & St.dev. & & & St.dev. & & & St.dev. & \\
\hline \multicolumn{16}{|l|}{ Random effects } \\
\hline Country (Intercept) & & 0.394 & & & 0.394 & & & 0.332 & & & 0.367 & & & 0.294 & \\
\hline Age at 1 st birth & & & & & & & & 0.048 & & & 0.048 & & & 0.03 & \\
\hline Middle level of education & & & & & & & & 0.184 & & & 0.123 & & & 0.075 & \\
\hline High level of education & & & & & & & & 0.262 & & & 0.218 & & & 0.241 & \\
\hline \multicolumn{16}{|l|}{ Number of cases } \\
\hline Macro-level (countries) & & 23 & & & 23 & & & 23 & & & 23 & & & 16 & \\
\hline Micro-level (person years) & & 33482 & & & 33177 & & & 33177 & & & 33177 & & & 23617 & \\
\hline
\end{tabular}

Notes: Significance levels (p): $* * *<0.001 ; * *<0.01 ; *<0.05 ;+<0.1 .{ }^{\circ}$ Country-level variable. All the other variables in models are individual characteristics of women. 
Figure 2:

Fitted shape of the baseline second-birth rate

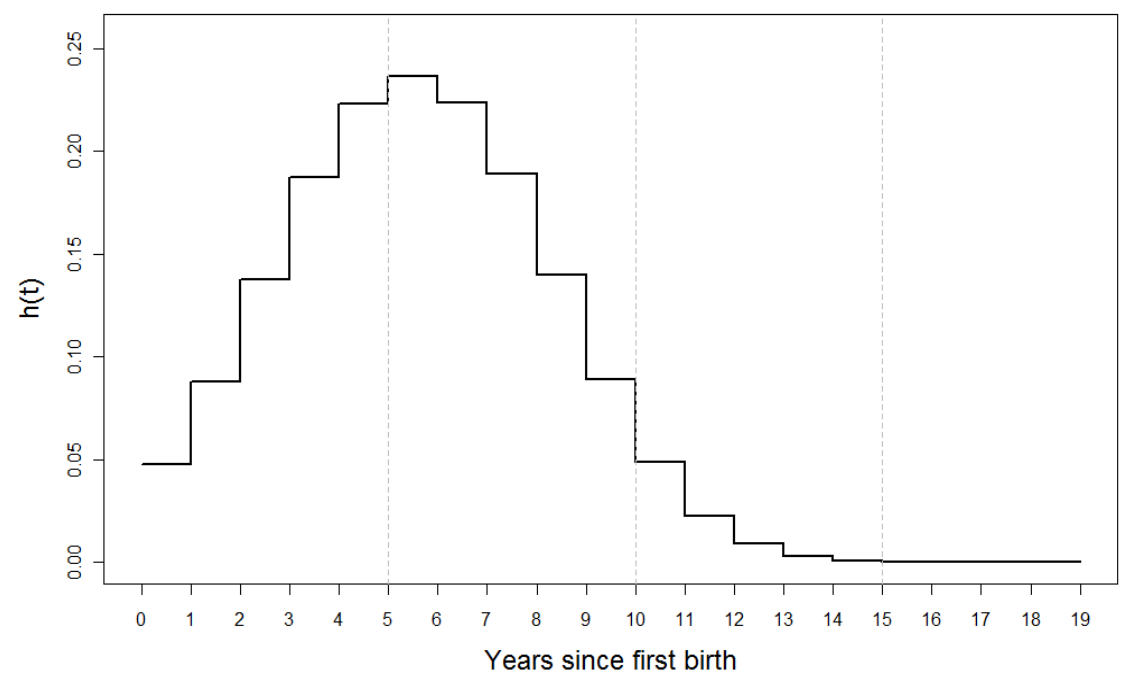

There are significant differences between countries, as illustrated by Figure 3 and indicated by a likelihood ratio test (comparing the deviance for Model I with the one for a model without country effects; $\operatorname{chi}^{2}=428, \mathrm{df}=1, \mathrm{p}<0.001$ ). The country parameters displayed in Figures 3 to 8 are the Best Linear Unbiased Predictors (also called Empirical Bayes Estimates) of the random country effects (see Agresti 2002), estimated with R's lmer function (part of the lme4 package, Bates and Sarkar 2007). Second-birth rates are estimated to be low, as expected, in southern and eastern European countries - with Portugal exhibiting exceptionally low rates, presumably exaggerated due to sampling error. They tend to be high in western and northern Europe. 
Figure 3:

Best Linear Unbiased Predictors of the random country effects in Model I; effects are on the scale of the logit

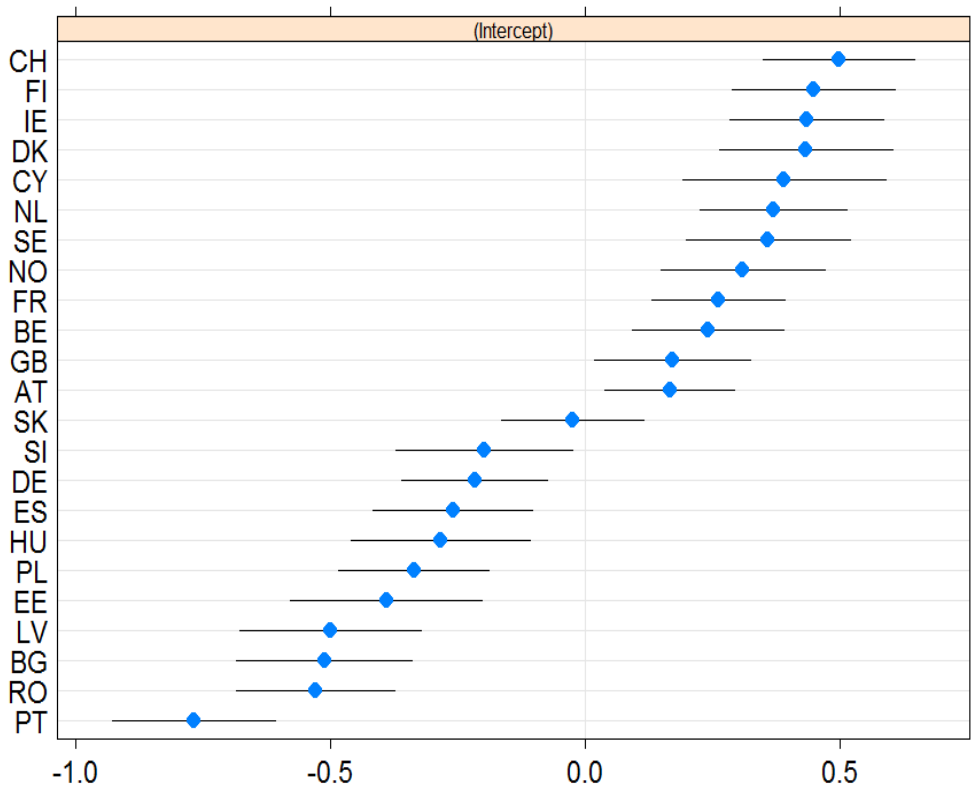

Note: Meaning of the country codes: AT Austria, BE Belgium, BG Bulgaria, CH Switzerland, CY Cyprus, DE Germany, DK Denmark, EE Estonia, ES Spain, FI Finland, FR France, GB Great Britain, HU Hungary, IE Ireland, LV Latvia, NL the Netherlands, NO Norwary, PL Poland, PT Portugal, RO Romania, SE Sweden, SI Slovenia, SK Slovakia

In order to assess the size of these country effects, the implications of the country effects are plotted on a natural scale in Figure 4. In order to construct that figure, we calculated the proportions expected to have a second child within five years after the birth of the first child (assumed to be born in 1996). The figure shows that the heterogeneity in second-birth rates in Europe can be considered large: the predicted percentages with a second child within five years range from around $40 \%$ in the countries from southern and eastern Europe to around 65\% in northern and western Europe. As can be seen in Figure 5, these differences are consistent with the idea that second-birth rates are to a large extent responsible for making the gap between ordinary low- and very-low-fertility countries. 
Figure 4:

Predicted probability to have a second birth within five years after first childbirth by country (first childbirth in 1996)

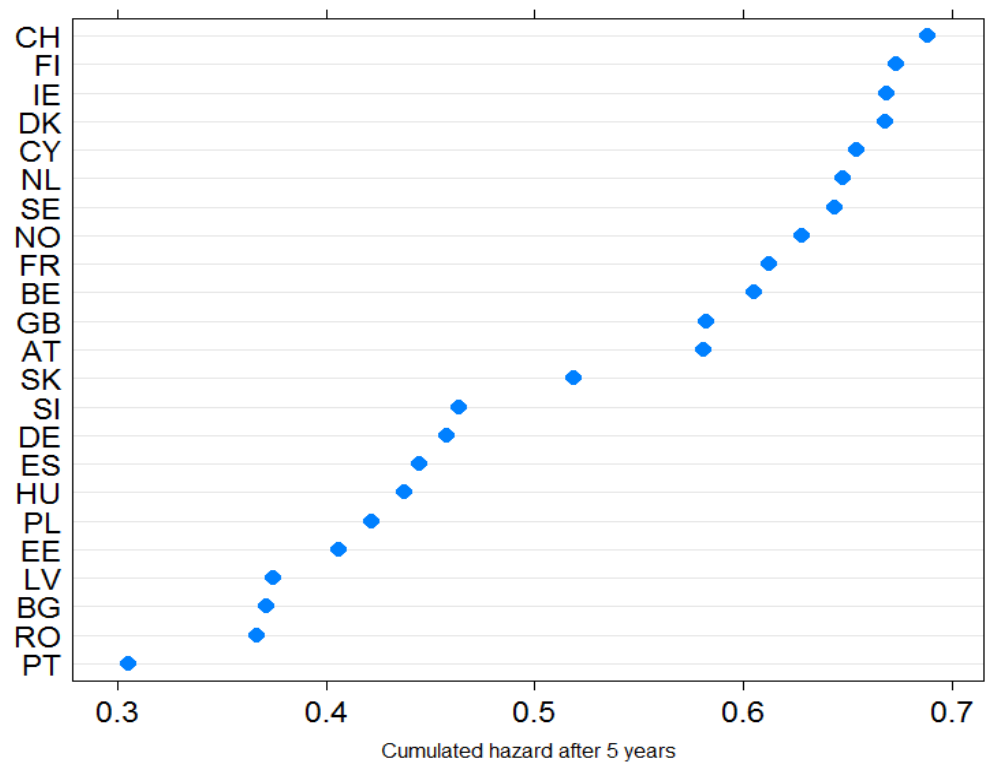

Figure 5:

Scatter plot with estimated country effects on conditional second-birth rates (logit scale) and total fertility rates for the year 2000

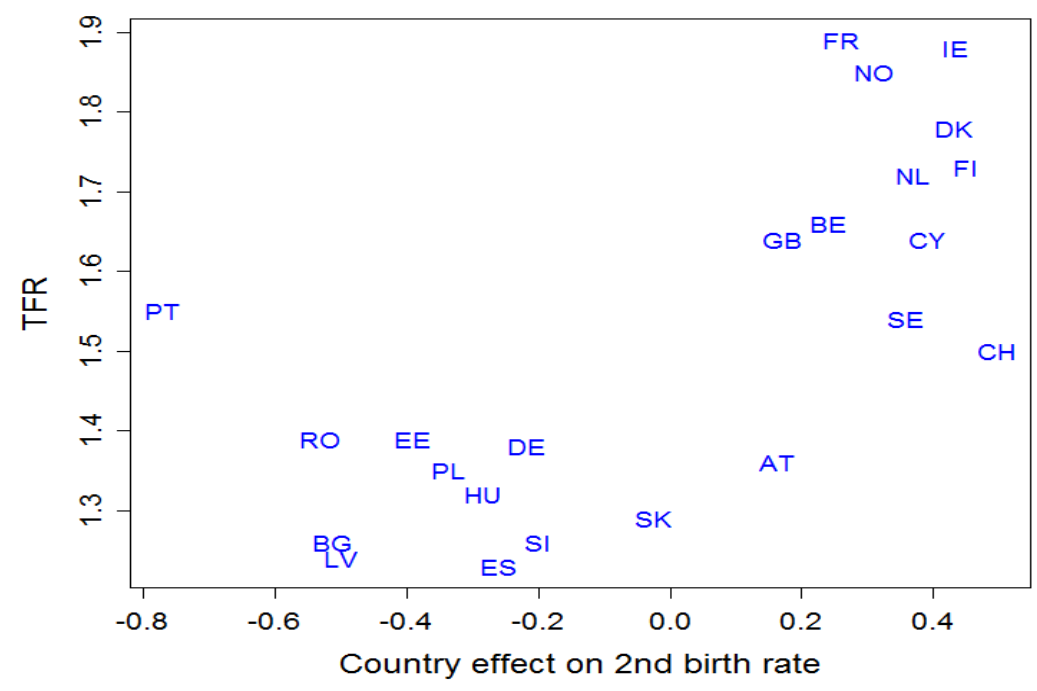


Model II just adds fixed effects for the mother's education level and age at first birth in order to see to what extent these country differences can be explained by the heterogeneous composition of these countries in terms of these two characteristics. Age at first birth is centred around its median value of 25 years and is included as a second-order polynomial in order to allow a non-linear effect. Education is included with two dummies for a medium and high level of education, low education being the reference category. No random slopes are estimated yet. Comparing the country effects of Models I and II we learn that the differences cannot be explained by differential first birth timing or composition by education level. Figure 6 shows that inclusion of these factors hardly changes the random effects at all and also the countries' rank order does not change very much.

Figure 6:

Estimated country effects with and without including education level and age at first birth (Model II versus Model I)

- Model I without age and education

Model II with age and education

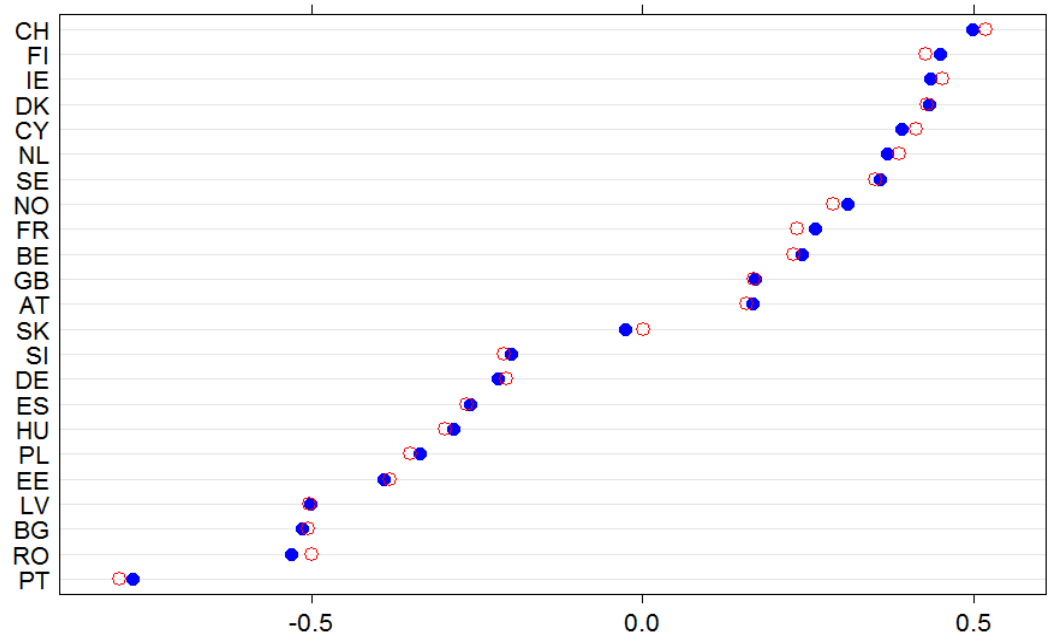

In Model II, there is not much of an effect, if any at all, of age at first birth on second-birth rates, on average across Europe. This may seem surprising given earlier findings that a later age at first birth is negatively associated with completed fertility and given the results of a simulation exercise suggesting that the postponement of first births leads to a rapid decline in second-birth rates (Billari and Borgoni 2005). It is less surprising, though, given the empirical evidence for a number of countries (including Sweden, France, Denmark and Austria) that substantial fertility delays have not actually led to declining secondbirth parity progression rates (Sobotka 2008: 39-40). The education level also has 
hardly any effect according to Model II. Presumably, the estimated effects of first-birth timing as well as of education in Model II are averaging out effects that are likely to be very heterogeneous across Europe.

Therefore, in Model III, the effects of age at first birth and the woman's education level are explicitly modelled to vary by country by including random slopes. Overall, on average across Europe (not weighted by population size), it appears now that there is a negative effect of age at first birth, as indicated by the significantly negative effect of the quadratic term. Below, we will explore country heterogeneity of the size of this effect on the natural scale of the dependent variable. Statistically, the overall effect of the education level across Europe is not significantly different from zero. However, there are statistically significant and substantially very important differences between European countries (see Figure 7).

Figure 7 shows that in countries that have relatively high second-birth rates overall, as indicated by their high-value intercept in the bottom left panel of the figure, the highly and medium educated tend to have higher second-birth rates than the less educated. This is the case, for example, in the Netherlands, Finland, Ireland, Sweden, Great Britain and Belgium (see the top right panel of Figure 7). In countries that have low second-birth rates overall (on the left hand side of the distribution of the bottom left panel of Figure 7), the highly or medium educated tend to have lower second-birth rates than the less educated. This is the case in Portugal, Bulgaria, Romania, Latvia and Poland, for example. In some cases, the confidence intervals are quite large but the pattern is clear and consistent. It suggests that the behaviour of the well-educated is crucial in making the difference between ordinary low and very low fertility.

In order to assess the different sizes of the effects of age at first birth by country, we have calculated, in the same way as above, the predicted proportions of having a second birth within five years after the birth of the first child. Since the effect of age at first birth not only differs by country but also is non-linear, it cannot be summarised in one number per country. Therefore, we calculated the predicted proportions with a second birth for three ages at first birth $(20,25$ and 30 years), which can then be compared in order to see how big a difference they make for each country. The results are shown in Figure 8. 
Figure 7:

Country differences in the effects of education level and age at first birth on the level of second-birth rates

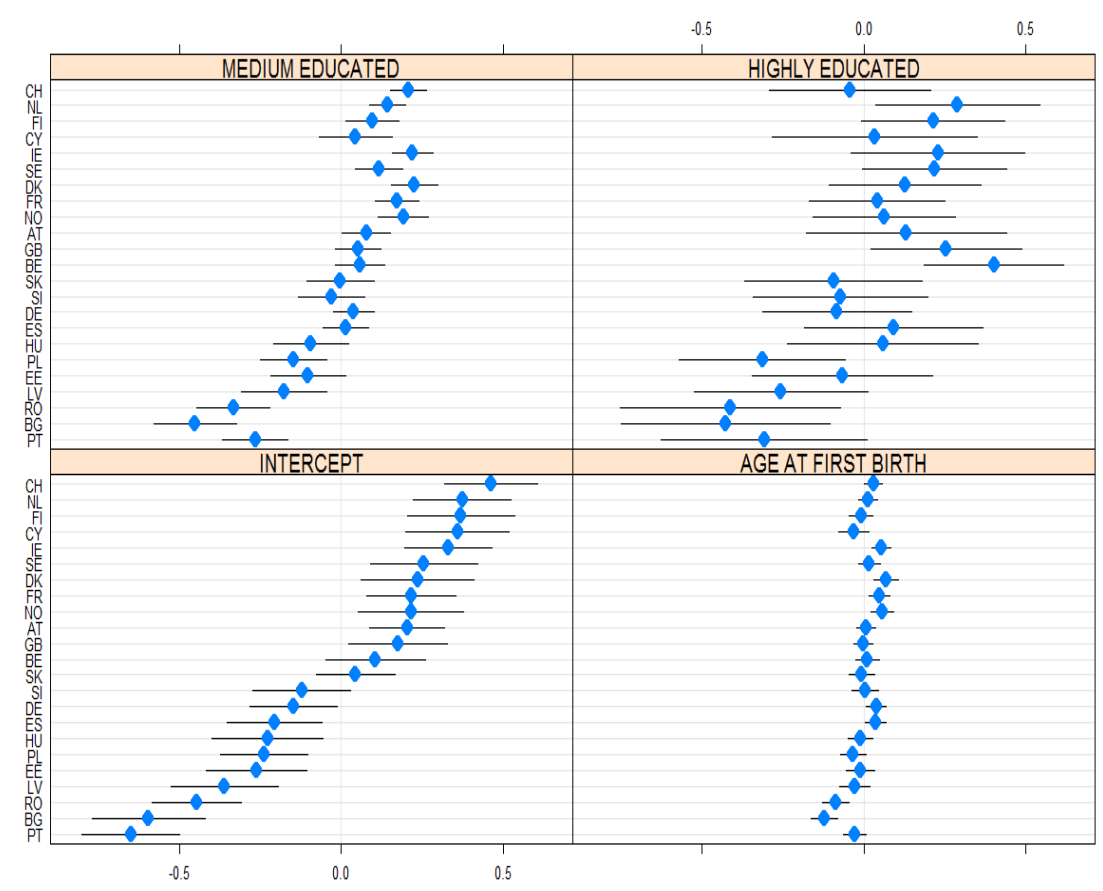

Figure 8:

Proportion with a second birth within five years by age at first birth and country

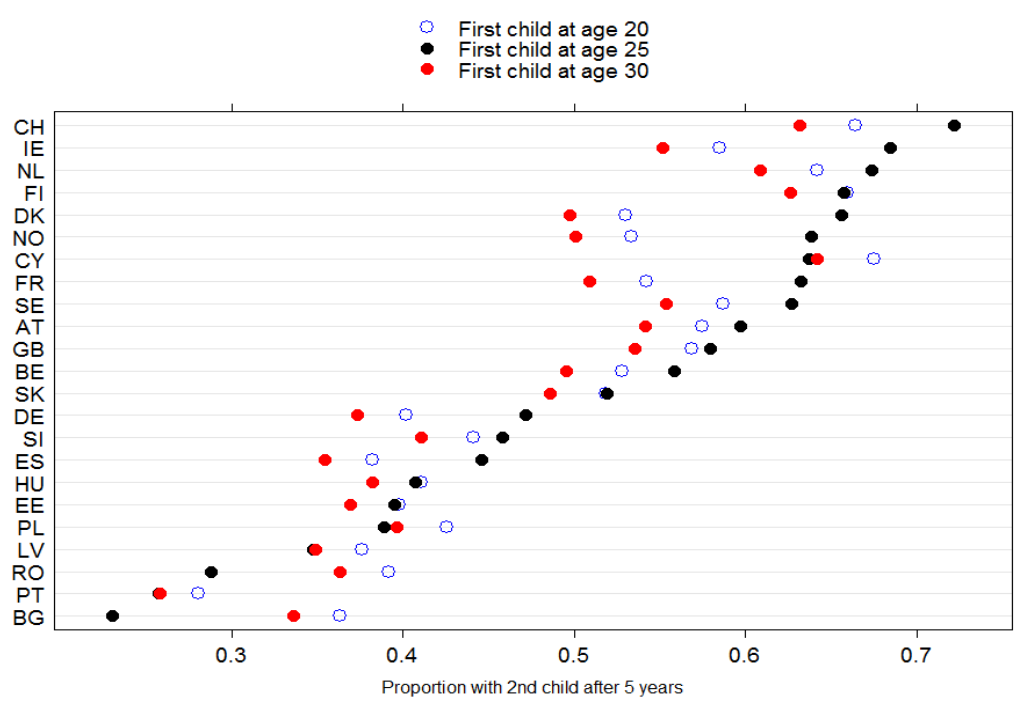


First, Figure 8 indicates that expected second-birth rates (cumulated for five years) are most often the lowest when the first child is born to a mother who has already reached age 30: the red dot is left in line for most countries. Yet, there are exceptions (Bulgaria, Romania and Poland) and the size of the age-at-first-birth effect differs very much between countries. Second-birth rates are particularly lower for women who became a mother at age 30 instead of age 25 in Ireland, Denmark, Norway and France. The differences in second-birth rates by these two ages at first birth are much smaller in Portugal, Cyprus, Latvia, Estonia, Poland and Hungary. Secondly, second-birth rates tend to be highest when the first birth occurred at an age that is closest to the historically and culturally expected age at (marriage and) first birth. That is: in countries that are close to the Hajnal line, where family formation is expected to occur earlier (Hajnal 1965; Watkins 1986), second-birth rates tend to be highest when the first child came at age 20. This is the case in Bulgaria, Romania, Latvia, Poland, Estonia and Hungary. In contrast, second-birth rates tend the be the highest among women who had their first child at age 25 rather than at age 20 in countries where the Malthusian marriage pattern has been dominating the demographic regime, i.e. farther to the west of the Hajnal line. In the following countries, second-birth rates tend to be higher for women who had their first child at age 25 instead of at the young age of 20 years: Switzerland, Ireland, the Netherlands, Denmark, Norway, France, Sweden, Austria, Great Britain, Belgium, Germany, and also Slovenia and Spain (the latter two rather pertain to the Mediterranean marriage pattern).

This suggests that the effects of the timing of the first birth on second-birth rates seem to be driven more by cultural forces than by a 'biological clock'. In countries where women are cultural-historically expected to become a mother at a young age, second-birth rates tend to be highest when the first child was born at a young age. In countries where women are cultural-historically expected to become a mother at a more advanced age, second-birth rates are highest when the first child came when the woman was indeed around age 25 instead of around age 20. Whether this interpretation is true or not, postponement effects on secondbirth rates across Europe are clearly not only a matter of declining fecundity with age ('the biological clock').

The effect of the timing of the first birth may not only vary by country but also by education level. Previous research suggests that more highly educated women may be more successful in catching up when a first birth has been postponed than the less educated. In order to assess whether there is such a pattern overall across Europe, Model IV includes product terms allowing for an interaction between the effect of age at first birth and the education level. The results in Table 2 show that there is a significant interaction. Figure 9 illustrates the importance and strength of the interaction. 
Figure 9:

Predicted proportions having a second birth within five years after the first birth, by age at first birth and education level

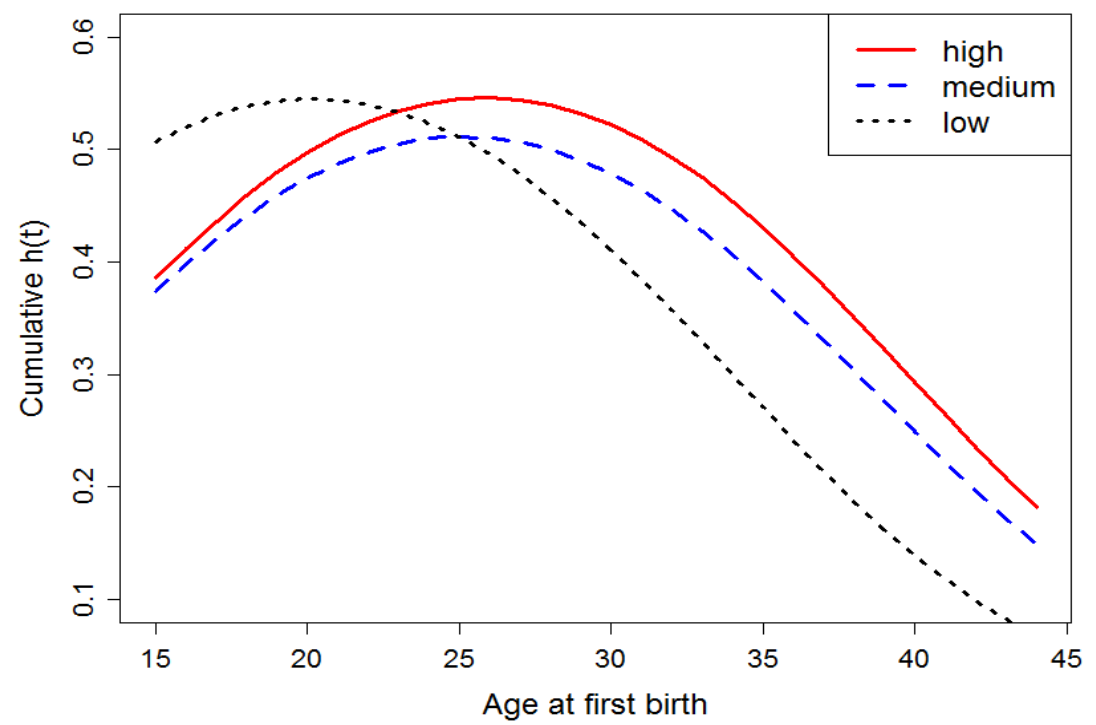

When women have their first birth around the modal age at first birth (age 25), there are hardly any differences, on average across Europe, between the lower, the medium and the more highly educated. Yet, when the first birth occurs at a higher age, big differences arise. When the first birth occurs around age 35, around $45 \%$ of the more highly educated women are expected to have at least a second birth five years later. For the less educated, this probability is only around $25 \%$. The medium educated are in between. So the model results are consistent with the idea that, on average across Europe, the more highly educated are catching up more than the less educated. At least to some extent, this will result from a selection process: the less educated are expected to have their first child at a lower age, so the ones who have their first child at advanced ages may be experiencing problems of fecundability.

If a first birth occurred at a particularly young age, say below age 20 , then second-birth rates are modelled to be higher for the low than for the highly educated - who may at the time of their first birth still be enrolled in higher education; the education level is measured at the time of the interview and may have been attained after the birth of the first child.

Finally, the question is to what extent these differences between countries and between education levels can be explained by the availability and the use of child care. Therefore, in a final step, we entered the day care enrolment rates into the equation as a country-level covariate. Since this variable is not available for all 
countries, the number of countries is limited to 16 in this analysis as opposed to 23 in the previous ones. The results can be seen in Table 2.

Child care enrolment appears to have a major effect on second-birth rates, but not for all women. For women with a low education level, it does not make a difference whether formal day care for young children is a widespread practice in their country or not. For highly educated women, it does make a big difference, as illustrated by Figure 10. Again, the medium educated are in between.

In order to show how high or low the enrolment rates actually were in these 16 European countries around 2004, Figure 10 includes 'country balls' at the bottom. Enrolment rates were lowest in Poland, Hungary, Germany and Austria. They were highest in Denmark but also high in Belgium, Sweden and Norway. The finding that high child care enrolment is associated with high second-birth rates among the more highly educated but not among the less educated is consistent with the idea the availability and acceptability of child care helps bringing down the opportunity costs of having an additional birth, and that this is particularly relevant for the highly educated.

\section{Figure 10:}

Proportion predicted to have a second child within 5 years after the first birth by country-level enrolment rate in child care and woman's education level**

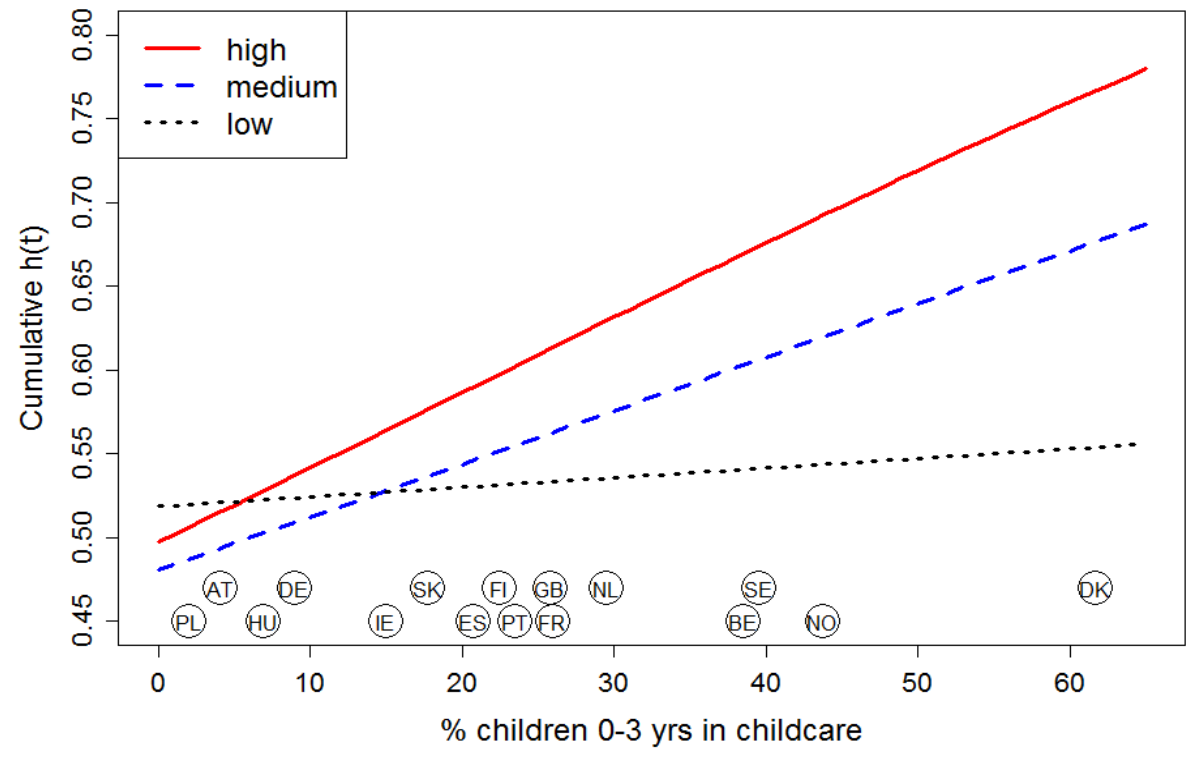

Note:* Predicted proportions for women who had their first child at age 25 in the year 1996. 


\section{Conclusions}

The country gradient of second-birth rates is large in Europe. Estimated probabilities to have a second child within five years after the first birth range from around $40 \%$, typically in central and eastern Europe but also in Portugal (just over 30\%) and Spain (about 45\%), to around 65\% in northern and western Europe. The differences are a major driving force behind the gap between very low and ordinary low fertility.

The effect of the timing of the first birth on second-birth rates is non-linear and differs by country. The results suggest that second-birth rates are highest when the first birth occurred at an age that is culturally considered 'normal' or 'expected'. That is: close to the Hajnal line, second-birth rates tend to be highest when the first birth occurred at a relatively young age (when the woman was under age 25). In contrast, farther west of that line they tend to be highest when the woman was somewhat older when she became a mother (say between age 25 and 30). This suggests that socio-cultural expectations about the 'proper age for motherhood' may be more important in explaining the effects of the first-birth postponements than declining fecundity with age (the 'biological clock'). This needs to be investigated in a future study.

The connection between education level and second-birth rates differs strongly by country: in some countries, high education is associated with lower second-birth parity progression rates than for the less educated. In other countries, high education is associated with higher second-birth rates than for less educated women. Note that the presented regression slopes for education should not be interpreted as pure causal effects of women's education level. For example, we have not anywhere controlled for the male partners' education levels, which may indeed have a stronger effect on second-birth rates than the female partner's education level (as in Germany and Austria, for example, see Kreyenfeld 2002 and Prskawetz and Zagaglia 2005, respectively). Since sexual partners tend to have similar levels of education, high male education is picked up by high female education in our models.

There are important interaction effects between the timing of the first birth and the education level: high age at first birth implies much lower second-birth rates for the less educated, while this is much less the case for the highly educated. So, our findings are consistent with the idea that the highly educated are more successful in catching up for delayed first childbearing than the less educated. This will at least to some extent represent a selection effect: the less educated are expected to have their first child at an earlier age, and among the ones who have their first child at a later age than expected, a relatively high proportion may be experiencing fecundity problems, for example.

The behaviour of the highly educated appears to be crucial for a country's overall fertility level: in countries where highly educated women have higher parity progression rates, total fertility tends to be relatively high overall. In 
countries where the highly educated have lower second-birth rates than the less educated, total fertility tends to be very low. It would be interesting to investigate in future work whether similar outcomes hold also for the transition to third births, which also contribute to fertility differences across Europe. How important are the effects of the age at first birth on differences in the transition to third births by country and education level? Would more highly educated women still be more successful in catching up higher-order births if they postponed their first birth?

High enrolment in child care is strongly associated with high second-birth rates, but only for the better educated. There is no effect of child care, on average across Europe, on second-birth rates for the less educated. This is consistent with the theory that the better educated have more to gain from child care availability and acceptability because they have a more elevated earning potential and, hence, face higher opportunity costs if taking young children to formal day care facilities is not a realistic option.

This study has some important limitations. First, our measure of enrolment in child care is a somewhat crude one. For example, it does not take into account the number of hours a child spends in day care per week. We know that there are large country differences in this matter which we have not taken into account. There is a trade-off to make in any cross-country research: on the one hand, ideally, we would want to use more detailed information about child care practices, but on the other hand, such data tend to be available only for some countries. And even if they are available, they are often incomparable. Therefore, we think that we need two kinds of studies. On the one hand, we need in-depth studies covering one or only a handful of countries but really addressing the issues in detail. On the other hand, we also need studies giving the big picture, without getting into the complexities of each single country. This study clearly belongs to the second type.

Another limitation is that we have used enrolment rates for around the year 2004, while most children studied were born in the years before that. Again, this is a data limitation that is not easily overcome. We assume for the time being that the rank order of countries has not changed a lot over the past two decades and hope that any between-country trends are not big enough to invalidate our results. We need more studies about this to be fully confident about this issue. Recent child care enrolment rates will probably correlate with other country differences, including family policies but also cultural characteristics like attitudes towards childrearing. It remains to be seen whether the reported effect of child care enrolment will still hold after controlling for such other country characteristics.

Finally, we have not been able to address the importance of reverse causality, i.e. to assess the extent to which child care enrolment rates are influenced by our dependent variable, i.e. second-birth rates. Maybe highly educated populations who want more second births have also been putting more pressure on their governments to invest in day care facilities. More generally, the regression 
parameters presented in this paper cannot be interpreted as estimates of a 'pure' causal effect, as understood in a counterfactual perspective. Many explanatory variables in our models can be considered endogenous for many reasons. The positive association between child care availability and second-birth rates among highly educated women may be caused by their prior preference structure. Therefore, we should not conclude that, if high child care availability were to be implemented in a country where child care availability actually is low, secondbirth rates would rise consequently. In order to make that happen, at least the cultural beliefs about working mothers and the pros and cons of day care have to be taken into account as well.

\section{Acknowledgements}

This research was sponsored by a grant from the Flemish Science Foundation (FWO-Vlaanderen). The authors are grateful to three anonymous reviewers of the Vienna Yearbook of Population Research for their comments on an earlier version of this paper.

\section{References}

Agresti, A. 2002. Categorical data analysis. Hoboken, Wiley.

Angrist, J. D. and J.-S. Pischke. 2009. Mostly Harmless Econometrics: An Empiricist Companion. Princeton, NJ, Princeton University Press.

Andersson, G., A.-Z. Duvander, and K. Hank, 2004. "Do child care characteristics influence continued child bearing in Sweden? An investigation of the quantity, quality, and price dimension." Journal of European Social Policy 14(4): 407-418.

Baizán, P. 2009. "Regional child care availability and fertility decisions in Spain." Demographic Research 21(27): 803-842.

Bates, D. and D. Sarkar. 2007. lme4: linear mixed-effects models using S4 classes. $R$ package version 0.9975-13.

Billari, F. C. and R. Borgoni. 2005. "Assessing the use of sample selection models in the estimation of fertility postponement effects." Statistical Methods and Applications 14(3): 389-402.

Billari, F. C. and H.-P. Kohler. 2004. "Patterns of low and lowest-low fertility in Europe." Population Studies 58(2): 161-176.

Breton, D. and F. Prioux. 2005. "Two children or three? influence of family policy and socio demographic factors." Population -E 60(4): 415-445.

Brewster, K. L. and R. R. Rindfuss. 2000. "Fertility and women's employment in industrialized nations." Annual Review of Sociology 26: 271-96.

Brodmann, S., G. Esping-Andersen, and M. Güell. 2007. "When fertility is bargained: second births in Denmark and Spain." European Sociological Review 23(5): 599-613.

Coleman, D. (ed.) 1996. Europe's Population in the 1990s. Oxford, Oxford University Press. 
De Henau J., D. Meulders, and S. O’Dorchai. 2007. "Making time for working parents. comparing public child care provision across EU-15." In: D. Del Boca, and C. Wetzels (eds.) Social Policies, Labour Markets and Motherhood: a Comparative Analysis of European Countries. Cambridge, Cambridge University Press, pp. 28-62.

Del Boca, D. 2002. "The effect of child care and part-time on participation and fertility of Italian women." Journal of Population Economics 15(3): 549-73.

Dribe, M. and M. Stanfors. 2009. "Does parenthood strengthen a traditional household division of labour? evidence from Sweden." Journal of Marriage and Family 71(1): $33-45$.

Ekert-Jaffé, O., H. Joshi, K. Lynch, R. Mougin, and M. Rendall. 2002. "Fertility, timing of births and socio-economic status in France and Britain. Social policies and occupational polarization." Population E-57(3): 475-507.

Engelhardt, H., H.-P. Kohler, and A. Prskawetz. 2009. "Causal analysis in population studies.” In: H. Engelhardt, H.-P. Kohler, and A. Prskawetz (eds.) Causal Analysis in Population Studies. Concepts, Methods, Applications, Berlin, Springer, pp. 1-7.

Ermisch, J. 1989. "Purchased child care, optimal family size and mother's employment." Journal of Population Economics 2:79-102.

European Commission. 2008. "Child care services in the EU." MEMO/08/592.

ESS Round 3: European Social Survey Round 3 Data. 2006. Data file edition 3.2. Norwegian Social Science Data Services, Norway - Data Archive and distributor of ESS data.

ESS Round 3: European Social Survey. 2008. ESS-3 2006 Documentation Report. Edition 3.2. Bergen, European Social Survey Data Archive, Norwegian Social Science Data Services.

Gauthier, A. H. 2007. "The impact of family policies on fertility in industrialized countries: a review of the literature." Population Research and Policy Review 26: 323-346.

Gerster, M., N. Keiding, L. B. Knudsen, and K. Strandberg-Larsen. 2007. "Education and second birth rates in Denmark 1981-1994.” Demographic Research 17(8): 295-330.

Goldstein, J., W. Lutz, and M. R. Testa. 2003. "The emergence of sub-replacement family size ideals in Europe." Population Research and Policy Review 22(5-6): 479-496.

Goldstein, J., T. Sobotka, and A. Jasilioniene, 2009. "The end of "lowest-low" fertility." Population and Development Review 24(4): 663-700.

Gustafsson, S. and F. P. Stafford. 1991. "Child care subsidies and labor supply in Sweden." Journal of Human Resources 27: 204-230.

Haan, P. and K. Wrohlich. 2009. "Can child care policy encourage employment and fertility? evidence from a structural model.” IZA Discussion Papers Paper $\mathrm{Nr} 4503$, October 2009, Bonn, Institute for the Study of Labor (IZA).

Hajnal, J. 1965. "European Marriage Patterns in Perspective." In: D. V. Glass and D. E. C. Eversley (eds.) Population and History. Essays in Historical Demography. London, Edward Arnold, pp. 101-43.

Hank, K. and M. Kreyenfeld. 2003. "A multilevel analysis of child care and women's fertility decisions in Western Germany." Journal of Marriage and Family 65(3): 584-596.

Hašková, H. 2010. "Factors contributing to the decline in child care services for children under the age of three in the Czech Republic.” In: Á. Scharle (ed.) Manka goes to work. Public child care in the Visegrad countries 1989-2009. Budapest, Budapest Institute for Policy Analysis, pp. 4-20. 
Hoem, B. and J. Hoem. 1989. "The impact of women's employment on second and third birth in modern Sweden." Population Studies 43(1): 47-67.

Hoem, J. 2005. "Why does Sweden have such high fertility?" Demographic Research 13(22): 559-572.

Kantorova, V. 2004. "Education and entry into motherhood: The Czech Republic during state socialism and the transition period (1970-1997)." Demographic Research 3(10): 245-274.

Klesment, M. and A. Puur. 2009. "Effects of education on second births before and after societal transition: evidence from the Estonian GGS." Paper presented at the 3rd TransEurope Workshop, Tallinn, 4-5 September 2009 «www.transeuropeproject.org»

Kohler, H.-P., F. C. Billari, and J. A. Ortega. 2006. "Low fertility in Europe: causes, implications and policy options." In: F. R. Harris (ed.) The Baby Bust: Who Will Do the Work? Who Will Pay the Taxes? Lanham, MD, Rowman and Littlefield Publishers, pp. 48-109.

Köppen, K. 2006. "Second births in Western Germany and France." Demographic Research 14(14): 295-330.

Kotowska, I., J. Jóźwiak, A. Matysiak, and A. Baranowska. 2008. "Poland: fertility decline as a response to profound societal and labour market changes." Demographic Research 19(22): 795-854.

Kotowska, I. E. and A. Matysiak. 2008. "Reconciliation of work and family under different institutional settings." In: Ch. Höhn, Avramov, D, and I. E. Kotowska (eds.) People, Population Change and Policies Vol.1: Family Change. The Hague, Springer Science+Business Media B.V., pp. 327-350.

Kravdal, Ø. 2001. "The high fertility of college educated women in Norway: an artefact of the separate modelling of each parity transition." Demographic Research 5(6): $187-216$.

Kravdal, Ø. 2007. "Effects of current education on second- and third-birth rates among Norwegian women and men born in 1964: Substantive interpretations and methodological issues." Demographic Research 17(9): 211-246.

Kreyenfeld, M. 2002. "Time-squeeze, partner effect or self-selection? An investigation into the positive effect of women's education on second birth risks in West Germany." Demographic Research 7(2): 15-48.

Kreyenfeld, M. and K. Hank. 2000. "Does the availability of child care influence the employment of mothers? Findings from western Germany." Population Research and Policy Review 19: 317-337.

Lappegård, T. and M. Rønsen. 2005. "The multifaceted impact of education on entry into motherhood." European Journal of Population 21(1): 31-49.

Lappegård, T. 2010. "Family policies and fertility in Norway." European Journal of Population 26(1): 99-116.

Lesthaeghe, R. and P. Willems. 1999. "Is low fertility a temporary phenomenon in the European Union?” Population and Development Review 25(2): 211-228.

Liefbroer, A. and M. Corijn. 1999. "Who, what, where, and when? specifying the impact of educational attainment and labour force participation on family formation." European Journal of Population 15(1): 45-75.

Lutz, W., V. Skirbekk, and M.R. Testa. 2005. "The low fertility trap hypothesis: Forces that may lead to further postponement and fewer births in Europe." European Demographic Research Papers 4. Vienna, Vienna Institute of Demography. 
Mills, M., L. Mencarini, M. L. Tanturri, and K. Begall. 2008. "Gender equity and fertility intensions in Italy and The Netherlands." Demographic Research 18(1): 1-26.

Morgan, S. P. and M. G. Taylor. 2006. "Low fertility at the turn of the twenty-first century." Annual Review of Sociology 32: 375-399.

Neels, K. 2006. Reproductive Strategies in Belgian Fertility, 1930-1990. Brussel/Den Haag, NIDI-CBGS Publications, 38.

Neyer, G. 2006. "Family policies and fertility in Europe: Fertility policies at the intersection of gender policies, employment policies and care policies." MPIDR Working Papers WP-2006-010, Rostock, Max Planck Institute for Demographic Research.

OECD. 2008. "PF11: Enrolment in day-care and pre-school." OECD Family Database, Public Policies for Families and Children. Paris, OECD.

Oláh, L. Sz. 1998. "Sweden, the middle way': A feminist approach." The European Journal of Women's Studies 5 (1): 47-67.

Oláh, L. Sz. 2003. "Gendering fertility: second births in Sweden and Hungary." population Research and Policy Review 22 (2): 171-200.

Philipov, D. 2002. "Fertility in times of discontinuous social change: the case of Central and Eastern Europe". MPIDR Working Paper WP-2002-024, Rostock, Max-Planck Institute for Demographic Research.

Prskawetz, A. and B. Zagaglia. 2005. "Second births in Austria." Vienna Yearbook of Population Research 2005: 143-170.

Rindfuss, R. R., D. Guilkey, S. P. Morgan, Ø. Kravdal, and K. B. Guzz. 2007. "Child care availability and first-birth timing in Norway." Demography 44(2): 345-372.

Robila, M. 2009. "Family policy in Eastern Europe: Developments and recommendations." Paper presented at the United Nations expert group meeting, UN Department of economic and social affairs - Division of social policy and development, Family Policy in a Changing World: Promoting Social Protection and Intergenerational Solidarity, Doha, Qatar, 14-16 April 2009.

Rostgaard, T. 2004. "Family support policy in Central and Eastern Europe - a decade and a half of transition." Early Childhood and Family Policy Series $\mathrm{Nr} 8$ - 2004, Paris, UNESCO Education Sector.

Sobotka, T. 2002. "Ten years of rapid fertility changes in European post-communist countries." Population Research Centre Working Paper Series 2002-1, Groningen, Population Research Centre.

Sobotka, T. 2004. Postponement of Childbearing and Low Fertility in Europe. Groningen/Amsterdam, Rijksuniversiteit Groningen/Dutch University Press.

Sobotka, T. 2008. "Does persistent low fertility threaten the future of European populations?" In: J. Surkyn, P. Deboosere, and J. Van Bavel (eds.) Demographic Challenges for the 21st century. A State of the Art in Demography. Brussel, VUB/Academia Press, pp. 27-89.

Spéder, Z. and F. Kamarás. 2008. "Hungary: Secular fertility decline with distinct period fluctuations." Demographic Research 19(18): 599-664.

Szelewa, D. and M. P. Polakowski. 2008. "Who cares? Changing patterns of child care in Central and Eastern Europe.” Journal of European Social Policy 18(2): 115-131.

Testa, M. R. and L. Grilli. 2006. "The effects of childbearing regional contexts on ideal family size in Europe: A multilevel analysis." Population - E 61(1-2): 109-138. 
Testa, M. R. 2007. "Childbearing Preferences and Family Issues in Europe: Evidence from the Eurobarometer 2006 Survey." Vienna Yearbook of Population Research 2007: 357-379.

Torr, B. M. and S. E. Short. 2004. "Second births and the second shift: A research note on gender equity and fertility." Population and Development Review 30 (1): 109-130.

Van Dijk, L. and J. J. Siegers. 1996. "The division of child care among mothers, fathers, and nonparental care providers in Dutch two-Parent families." Journal of Marriage and the Family 58: 1018-1028.

Viitanen, T. K. 2005. "Cost of child care and female employment in the UK." Labour 19 (Special Issue): 149-170.

Watkins, S. C. 1986. "Regional patterns of nuptiality in Western Europe, 1870-1960." In: A. J. Coale and S. C. Watkins (eds.) The Decline of Fertility in Europe. Princeton, Princeton University Press, pp. 314-36. 